
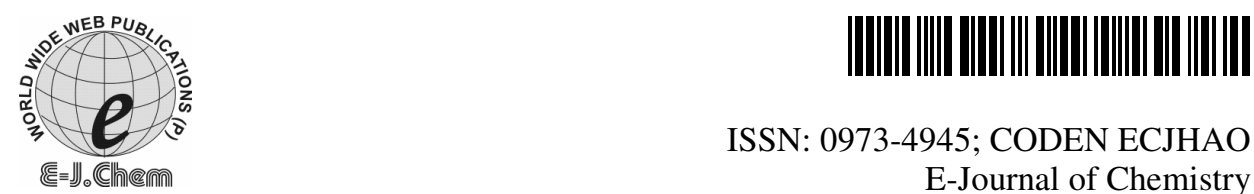

ISSN: 0973-4945; CODEN ECJHAO

http://www.e-journals.net

E-Journal of Chemistry

2011, 8(2), 739-747

\title{
Adsorption Study of Some Sulphanilic Azo Dyes on Charcoal
}

\author{
H. J. MOHAMMED*, B. J. KADHIM ${ }^{\S}$ and ASEEL SH. MOHAMMED \\ Dept of Basic Science, College of Dentistry, Kufa University, Iraq \\ ${ }^{\S}$ Dept of Food Science, College of Agriculture, Kufa University, Iraq \\ ibrahiem_af@yahoo.com
}

Received 29 March 2010; Accepted 23 July 2010

\begin{abstract}
Studies on the removal of two dyes (sulphanilic azo antipyrine and sulphanilic azo imidazole) from aqueous solution by adsorption on charcoal as an adsorbent were carried out. A series of experiments were under taken in a batch adsorption technique to access the effect of the process variables i.e. contact time, initial dye concentration, initial $\mathrm{pH}$, adsorbent dose and temperature. Adsorbent dosage $(0.1 \mathrm{~g})$ higher value for both dyes. The equilibrium in the solution was observed within $(35 \mathrm{~min})$ of two sulphanilic dyes on charcoal. The equilibrium isotherms for both dyes were determined to describe the adsorption process. The results showed that the equilibrium data was fitted by of the Freundlich isotherms on charcoal surface. The result obtained shows that the adsorption isotherm for both dyes on charcoal was according to Giles classification. The thermodynamic factors such as $\Delta \mathrm{H}, \Delta \mathrm{G}$ and $\Delta \mathrm{S}$ were calculated.
\end{abstract}

Keywords: Charcoal, Adsorption, Organic dyes, Sulphanilic azo dye.

\section{Introduction}

Charcoal is often used as an adsorbent for the removal of a different of organic dyes because it is highly inert and thermally stable, it can also be used at different hydrogen function range ${ }^{1}$. Activated carbon is the most commonly used adsorbent, although other materials such as activated clay, wood and types of cellulose have also been studied ${ }^{2,7}$. Some of azo compounds are stable and do not suffer biodegradation and those including metals are toxic. Consequently it is important to remove these pollutants from the wastewaters before their final disposal ${ }^{8,9}$. Adsorption methods have been reported as an effective process to remove organic dyes from wastewaters. The widely used adsorbent for industrial residue is activated carbon $^{10,11}$. Many methods including coagulation precipitation, filtration and oxidation have been used for the treatment of dye-containing effluents ${ }^{12,13}$. These methods are costly and can not be used effectively to treat the wide range of dye wastewaters when compared with 
adsorption processes. The aim of this study was to determine the adsorption capacity of charcoal in aqueous organic dyes varying with process factors including initial dye concentration, contact time, initial $\mathrm{pH}$, adsorbent dose and temperature.

\section{Experimental}

All spectral and absorbance measurements were carried out on APEL - PD - 303 UV visible recording spectrophotometer. Shaking inductor GCA/precision scientific Chicago, U.S.A and Maga fuge 1.0 Herouse centrifuge were used .A digital $\mathrm{pH}$ meter Hanna was used. The charcoal sample used as adsorbent was supplied from India where as the sulphanilic azo imidazol and sulphanilic azo antipyrine were prepared according to the equations by Hussain $^{14}$ (Scheme 1).
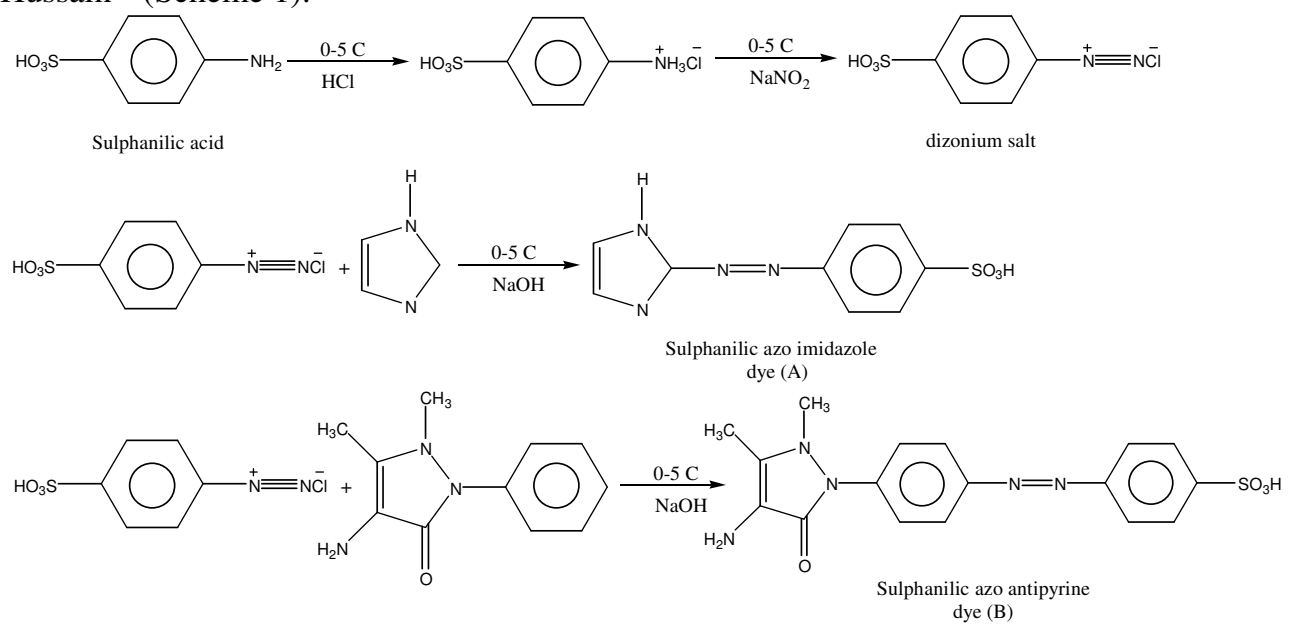

Scheme 1. Preparation of dyes

Table 1. Structures, molecular weights and wavelengths of the dyes

$\begin{array}{ccc}\text { Name } & \begin{array}{c}\text { Molar } \\ \text { mass }\end{array} & \lambda_{\max } / \mathrm{nm} \\ \begin{array}{c}\text { Sulphanilic } \\ \text { azo imidazole antipyrine } \\ \text { (B) }\end{array}\end{array}$

\section{General procedure for isotherms}

Portions of dye (A or B) solution, $15 \mathrm{~mL}$ of known initial concentration (10 - $100 \mathrm{ppm})$ and varied amounts of charcoal $(0.02-0.12 \mathrm{~g})$ were poured into volumetric flask. Analytical determination of sulpanilic azo imidazol or sulpanilic azo antipyrine in solutions after equilibrium (35 $\mathrm{min}$ at $25^{\circ} \mathrm{C}$ ) were performed by means of a APEl-PD 303 spectrophotometer. Optical densities were determined at $410 \mathrm{~nm}$ for dye A and at 370 for 
dye $\mathbf{B}$ (Figure $1 \& 2$ ) which corresponds to the maximum absorption peak of dye $\mathbf{A}$ and $\mathbf{B}$. From the difference between initial concentration and equilibrium, the amounts of dye $\mathbf{A}$ and $\mathbf{B}$ adsorbed were calculated by the following relation:

$$
Q e=\frac{(C o-C e) \mathrm{V}_{\text {sol }}}{\mathrm{M}}
$$

Where, $\mathrm{Q}_{\mathrm{e}}$ amount of dye adsorbed $\left(\mathrm{mg}^{\mathrm{g}} \mathrm{g}^{-1}\right), \mathrm{C}_{\mathrm{o}}$ and $\mathrm{C}_{\mathrm{e}}$ are the initial and equilibrium concentration (mg. $\mathrm{L}^{-1}$ ) respectively. $\mathrm{M}$ is the adsorbent dosage (in $\mathrm{g}$ ), $\mathrm{V}_{\text {sol }}$ is the solution volume (in $\mathrm{mL}$ ). The adsorption capacity was determined with the effect of contact time, initial concentration of dye $\mathbf{A}$ and $\mathbf{B}, \mathrm{pH}$, temperature and agitation rate. The equilibrium concentration, adsorption capacity at equilibrium was determined to fit in the adsorption isotherms.

\section{Calibration graphs of two dyes}

In to a series of ten calibrated flask, different volumes of dye $\mathbf{A}$ and $\mathbf{B}$ working solution (100 mg. $\mathrm{mL}^{-1}$ ) were transferred to cover the range of the calibration curve. Linear calibration graphs of two dyes were obtained, that obeyed Beer's law over the concentration range of (10 - $100 \mathrm{ppm})$ with correlation coefficient $0.9981,0.9889$ and an intercept of 0.2 , 0.53 for dye $\mathbf{A}$ and $\mathbf{B}$ respectively.

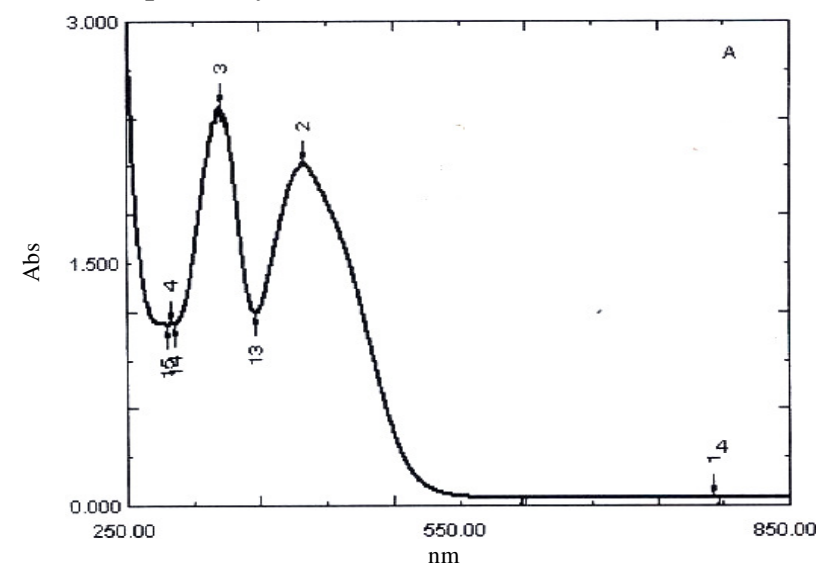

Figure 1. Spectrum of sulphanilic azo imidazole dye A

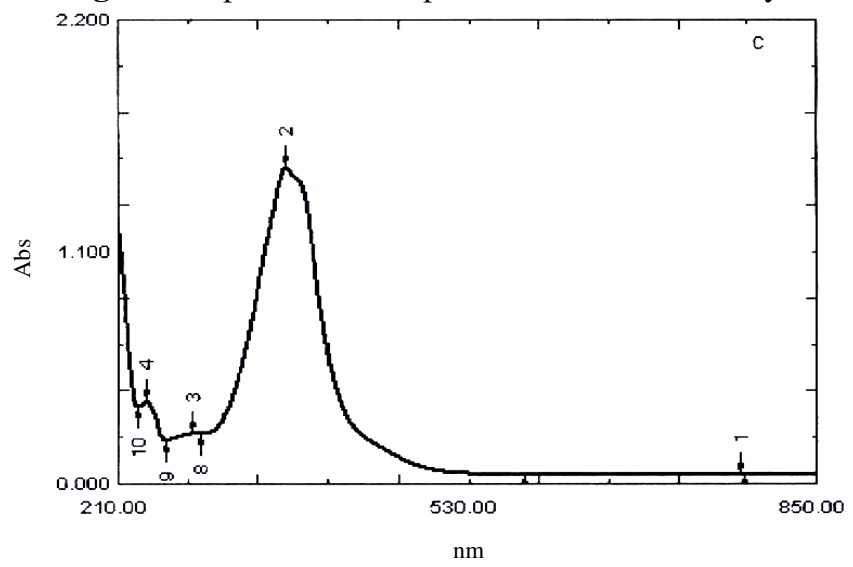

Figure 2. Spectrum of sulphanilic azo antipyrine dye B 


\section{Results and Discussion}

\section{Adsorption isotherms}

The Freundlich models are the most frequently employed models. The Freundlich isotherms have been widely adopted to characterize the adsorption capacity of dyes pollutant using different adsorbent by fitting the adsorption data (Figure 3).



Figure 3. Adsorption isotherms of dye $\mathbf{A}$ and $\mathbf{B}$ at $\mathrm{pH} 12$ and 2 respectively

The Freundlich isotherms have the general from such as:

$$
\mathrm{Qe}=\mathrm{K}_{\mathrm{f}} \mathrm{Ce}^{1 / 2}
$$

This equation can be modified as:

$$
Q e=\frac{C o-C e}{\mathrm{M}}=K_{\mathrm{f}} C e^{1 / 2}
$$

Where, $\mathrm{K}_{\mathrm{f}}$ and $1 / \mathrm{n}$ are Freundlich constants related to adsorption capacity and adsorption intensity, respectively, of the sorbent. The values of $K_{f}$ and $1 / n$ can be obtained from the intercept and slope respectively of the linear plot of experimental data of log $\mathrm{Q}_{\mathrm{e}}$ versus $\log$ $\mathrm{C}_{\mathrm{e}}$ (Table 2 Figure $4 \& 5$ ).

Table 2. Frundlich constant for two dyes in aqueous solution using charcoal as an adsorbent

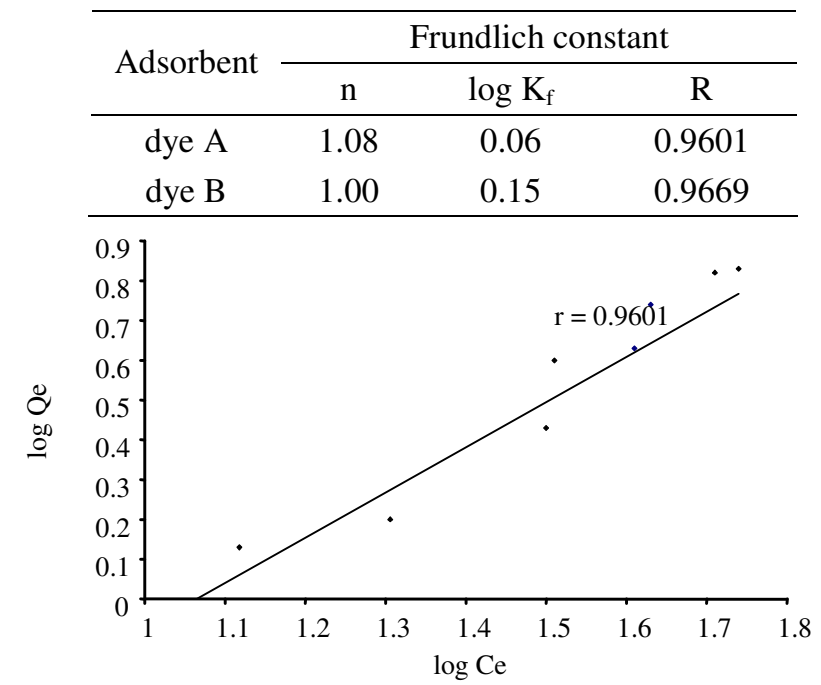

Figure 4. Freundlich isotherm of dye A with charcoal at pH 12 


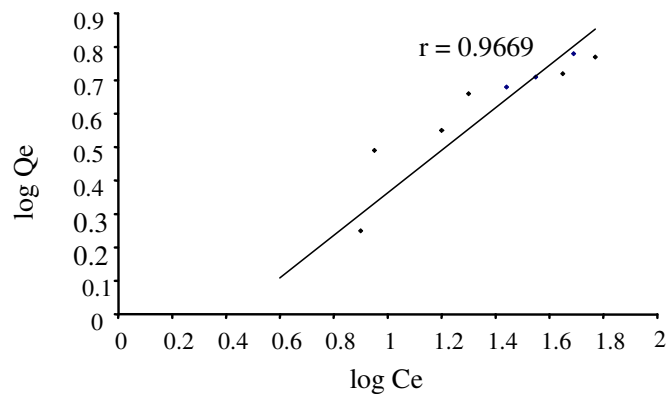

Figure 5. Freundlich isotherm of dye $\mathbf{B}$ with charcoal at $\mathrm{pH} 2$

$$
\log \mathrm{Qe}=\log \mathrm{K}_{\mathrm{f}}+1 / \mathrm{n} \log \mathrm{Ce}
$$

The values showed that the equilibrium data for two dyes fitted well to the Freundlich isotherms in the studied concentration ranges. Based on the correlation coefficients ( $r$ ) the equilibrium data was fitted in the isotherms Freundlich equations (Table 2).

Many authors have used these isotherm to evaluate the adsorption capacity by different adsorbent with different dyes ${ }^{15,16}$. The results showed that the adsorption of dye $\mathbf{A}$ and $\mathbf{B}$ on charcoal was found to be effective at $\mathrm{pH} 12$ and 2 respectively. The Freundlich equations were used to study data concerning the dependence of the adsorption of two dyes on charcoal at $\mathrm{pH} 12$ and 2.

The adsorption constants evaluated from the isotherms with correlation coefficient are (Table 2) very high, regression coefficient $(0.9601,0.9669)$ was found for dye $\mathbf{A}$ and $\mathbf{B}$ respectively. The regression values showed that the equilibrium data for dyes fitted well to the Freundlich isotherm in the studied concentration ranges.

\section{Effect of $p H$}

In order to study the hydrogen ion concentration $(\mathrm{pH})$ on sulphanilic azo imidazole and sulphanilic azo antipyrine by adsorbent charcoal, dyes solutions were prepared in the range of $10-100 \mathrm{ppm}$ and adjusted to different $\mathrm{pH}$ values $(2,4,7,9$ and 12) using $0.1 \mathrm{~N}$ of $\mathrm{HCl}$ and $0.1 \mathrm{~N}$ of $\mathrm{NaOH}$. The results are shown in Figure $6 \& 7$. It is clear that the amount of dyes removed at various $\mathrm{pH}$. $\mathrm{pH} 12$ produces a large adsorbed quantity for dye $\mathbf{A}$, whereas $\mathrm{pH} 2$ produces a large adsorbed quantity for dye $\mathrm{B}$. It is clear that, the lower $\mathrm{pH}$ value (Figure 6) explained on the basis of formation of a positively charged surface on charcoal.

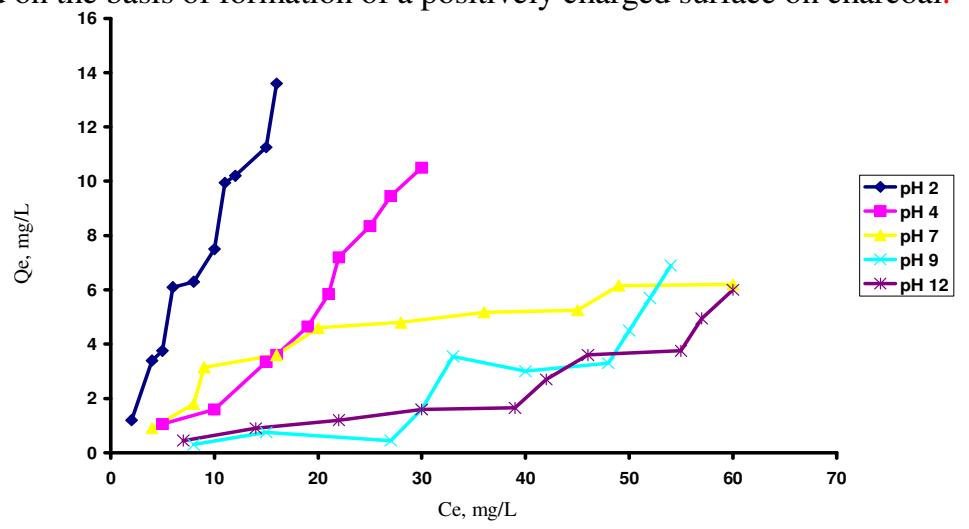

Figure 6. Removal of colour from aqueous solution of sulphanilic azo antipyrine at various $\mathrm{pH}$ 
At solution $\mathrm{pH}$ acidic, the removal capacity was expected to decrease, as the adsorbent was positively charged and the dye molecules were neutral charged Figure 7.

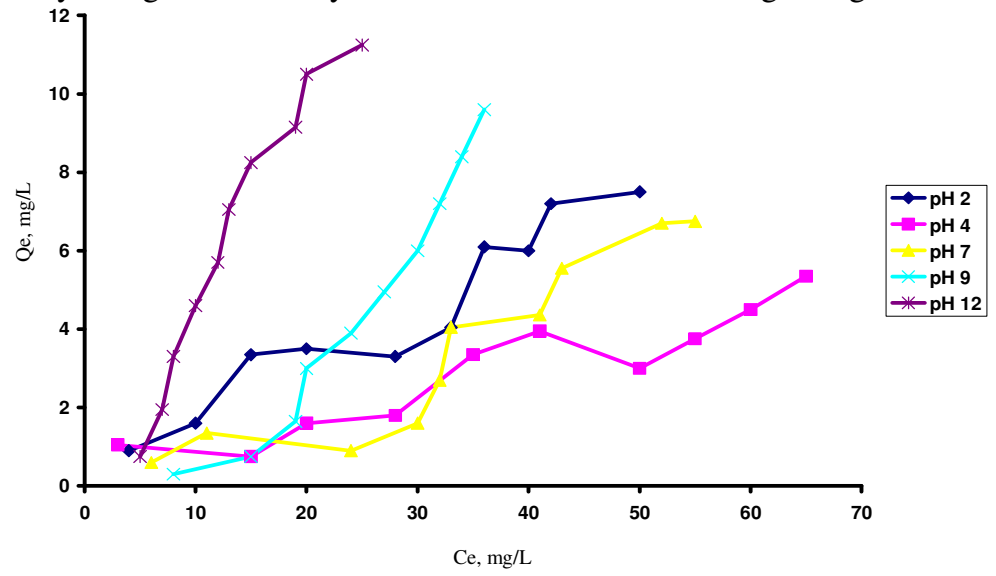

Figure 7. Removal of colour from aqueous solution of sulphanilic azo imidazole at various $\mathrm{pH}$

\section{Contact time}

The influence of the contact time on the adsorption capacity of two dyes by adsorbent charcoal was conducted through batch experiments to achieve the equilibrium as shown in Figure 8.

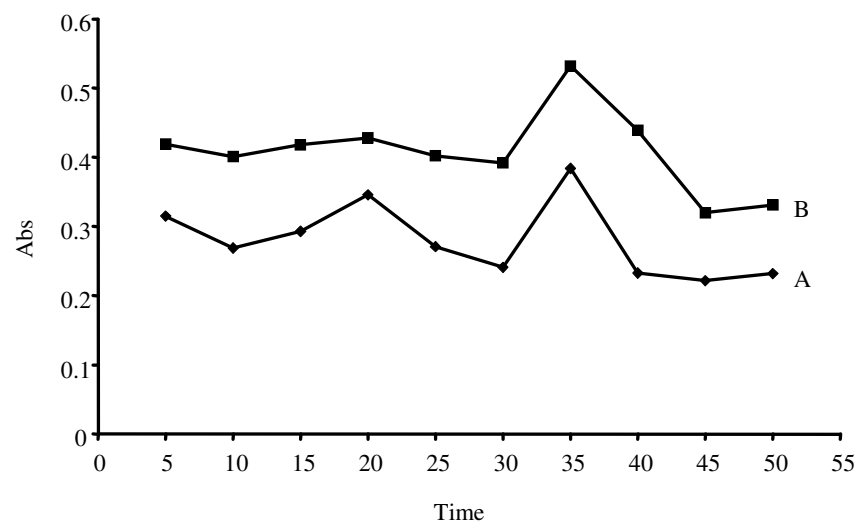

Figure 8. Adsorption capacity against contact time of dyes $\mathbf{A}$ and $\mathbf{B}$ with charcoal

The results indicated that the high affinity between the sorbent surface and the reactive dye molecules the dye molecule favorably adsorb on the carbon surface with low competition from water molecule

\section{Adsorbent dosage}

In order to study the effect of adsorbent dosage on dyes removal as the adsorption capacity with fixed initial concentration of type of dye, $\mathrm{pH}$, temperature ,agitation rate and charcoal as an adsorbent. Different weight of dosage was used (0.02, 0.03, 0.05, 0.07, 0.09, 0.10 and $0.12 \mathrm{~g}$ ). The maximum removal of dyes was observed with the dosage more than $0.09 \mathrm{~g}$ and $0.1 \mathrm{~g}$ used for all subsequence experiments. 


\section{Effect of temperatures}

Adsorption isotherms were taken for the dyes in the temperature range of 298 to $313 \mathrm{~K}$. The results are shown in Figure $9 \& 10$. The thermodynamic parameters $\ln K, \Delta \mathrm{G}, \Delta \mathrm{S}$ and $\Delta \mathrm{H}$ were computed.

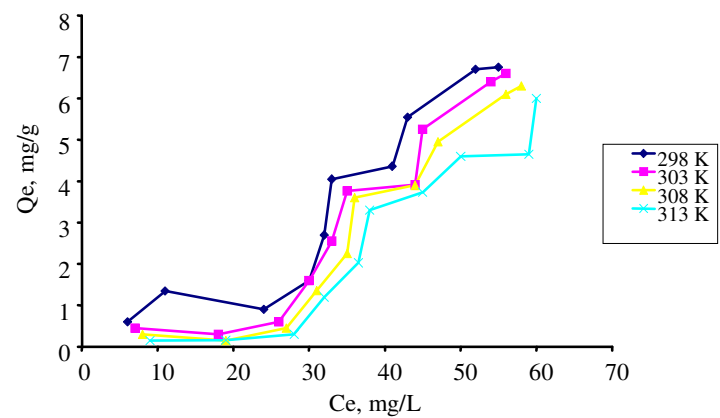

Figure 9. Effect of temperature on the adsorption capacity of dye A with charcoal at pH 12

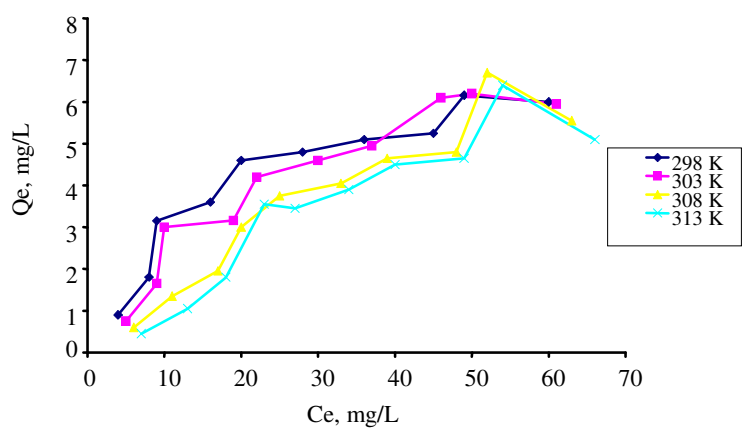

Figure 10. Effect of temperature on the adsorption capacity of dye $\mathbf{B}$ with charcoal at $\mathrm{pH} 2$ The free energy change $(\Delta \mathrm{G})$ was calculated from the relation ${ }^{18}$

$$
\Delta \mathrm{G}=-\mathrm{RT} \ln \mathrm{K}
$$

Enthalpy change $(\Delta \mathrm{H})$ was computed from the following (Van Hoff-Arrhenius equation ${ }^{19}$ ).

$$
\log \mathrm{Xm}=\frac{-\Delta \mathrm{H}}{2.303 \mathrm{RT}}+\mathrm{con}
$$

And the entropy was calculated from the equation ${ }^{20}$

$$
\Delta \mathrm{G}=\Delta \mathrm{H}-\mathrm{T} \Delta \mathrm{S}
$$

The thermodynamic factors evaluated from isotherms are shown in Table 3.

Table 3. Thermodynamic values of sulphanilic dyes in aqueous solution using charcoal as an adsorbent

\begin{tabular}{cccc}
\hline Dyes & $\Delta \mathrm{H}, \mathrm{kJ} \cdot \mathrm{mol}^{-1}$ & $\Delta \mathrm{G}, \mathrm{kJ} \cdot \mathrm{mol}^{-1}$ & $\Delta \mathrm{S}, \mathrm{J} \cdot \mathrm{mol}^{-1}$ \\
\hline $\mathbf{A}$ & -4.94 & 5.196 & -0.034 \\
B & -7.41 & 5.70 & -0.043 \\
\hline
\end{tabular}

The up take of two dyes decreases with an increasing temperature up to $40{ }^{\circ} \mathrm{C}$. The results indicated that the adsorption process is endothermic in nature ${ }^{21,22}$. Many variables such as the molecular volume of the dyes, its planarity and its ability to bind to the adsorbent, among others, can affect the degree of adsorption. 
The two temperatures was the favorite for adsorption of sulphanilic azo dyes on charcoal due to the thickness of the boundary layer decrease with the increase in solution temperature. Therefore, the increasing tendency of dyes to escape from the solid phase to the liquid phase, as a result of increase in kinetic energy of the adsorbent species at high temperature ${ }^{23}$.

More dye $\mathbf{B}$ is adsorbed on charcoal than dye $\mathbf{A}$ dye. This difference is most related to the higher affinity of the dye $\mathbf{B}$ on the charcoal surface. Also this may be due to a tendency for the dye A molecule to escape from the solid phase of charcoal to the liquid phase of dye with an increase in temperature of the solution ${ }^{24}$ Figure $11 \& 12$.

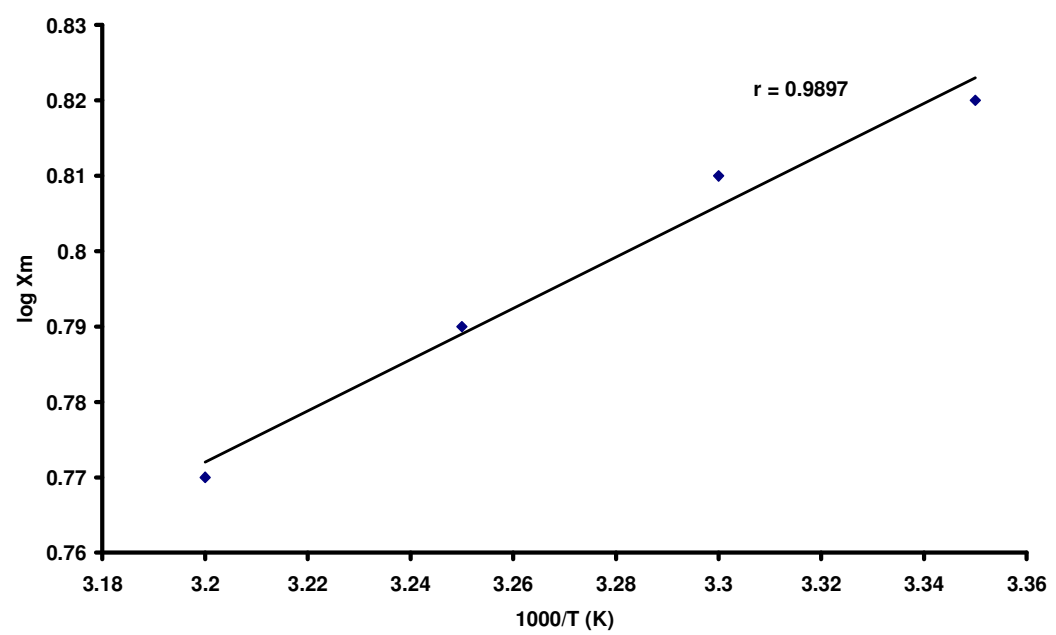

Figure 11. Relationship between the $\log \mathrm{Xm}$ and $1 / \mathrm{T}$ of dye $\mathbf{A}$ with charcoal as an adsorbent

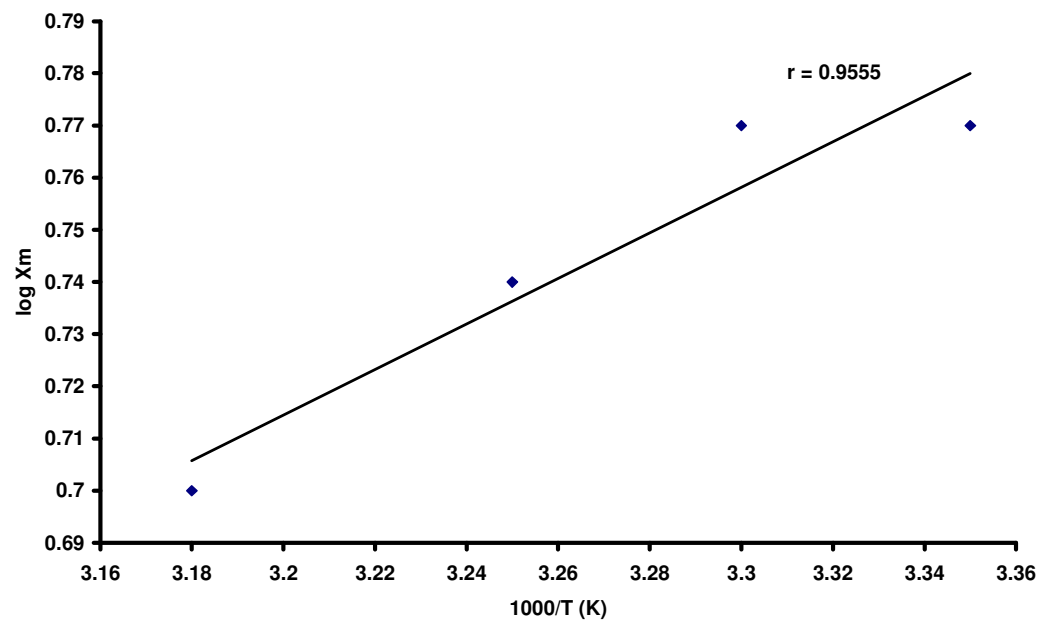

Figure 12. Relationship between the $\log \mathrm{Xm}$ and $1 / \mathrm{T}$ of dye $\mathbf{B}$ with charcoal as an adsorbent

The apparent adsorption enthalpy is $-4.49 \mathrm{kcal} / \mathrm{mol}$ for the sulphanilic azo imidazole dye and $-7.41 \mathrm{kcal} / \mathrm{mol}$ for sulphanilic azo antipyrine. The low value of adsorption enthalpy indicates a physical adsorption ${ }^{17}$. 


\section{References}

1. Halhouli Kh A, Darwish.N A and Aldhoou.N M, Sep Sci Technol., 1995, 30, 3313.

2. Mckay G and Al-duri, B; Trans IChemE Part B, 1990, 68, 255.

3. Nassar M M and Mohammad S El-Geundi, J Chem Tech Biotechnol., 1990, 50, 257-264.

4. Yeh R and Thomas, J Chem Tech Biotechnol., 1995b, 63, 48.

5. Safarik I; Nymburska K and Safarikova M, J Chem Tech Biotechnol., 1997, 69, 1-4.

6. Qadeer R and Rehan A H, Turk J Chem., 2002, 26, 357-361.

7. Zahangir A, Biotechnol., 2004, 3(2), 200.

8. Gupta G S, Shuckla S P, Prasadand G and Singh V N, Environ Tech., 1992, 13, 925.

9. Ceyhan.O and D Baybas D,.Turk J Chem., 2001, 25, 193 .

10. Kalil L B and Girgis B S, Adsorpt Sci Technol., 1998, 16, 405

11. Walker G M and Weatherley L R,.Process Biochem., 1997, 32, 327-336.

12. Diaper C, Correia V M and Judd S J, J Soc Dyers Color., 1996, 112, 273 .

13. Stephenson R.J and Duff S.J B, Water Res., 1996, 30, 781-792.

14. Hussain J M, Athraa.H, Jamal M R, J Al-Nahrain Uni., 2010, 36, 85.

15. Yahya S Al-Degs, Musa I, Amjad H El-Sheikh and Garin M W, Dyes and Pigments 2008, 77, 16.

16. Oguz L and Fatma T, Turk J Chem., 2000, 24, 9.

17. Moreika R F P M, Peruch M G and Kuhnen N C, Braz J Chem Eng., 1998, 15, 210 .

18. Panday .K K, Gup P and Singh V N, Water Res., 1985, 19, 869.

19. Weber W J, Asce and Morris A M, Div Am Soc Civ Eng., 1963, 89, 31-59.

20. Namasivayam C and Kavitha D, Dyes and Pigments, 2002, 54, 47.

21. Chu C H and Chem K M, Process Biochem., 2002, 37(6), 595 .

22. Ahmed.N.M and Ram R N, Environ Pollut., 1992, 77, 79-86.

23. Vindo V and Anirudham T, J Chem Technol Biotechnol., 2001, 77, 92-101.

24. HO Y and Mckay G, Trans Chem., 1998, 76, 183-191. 


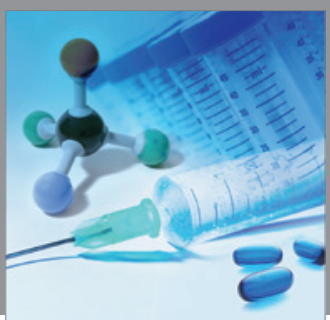

International Journal of

Medicinal Chemistry

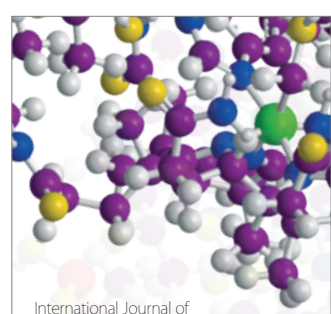

Carbohydrate Chemistry

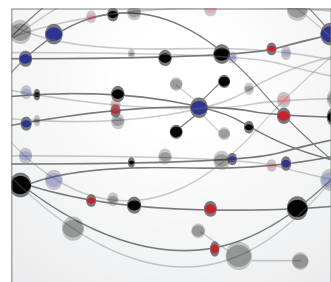

The Scientific World Journal
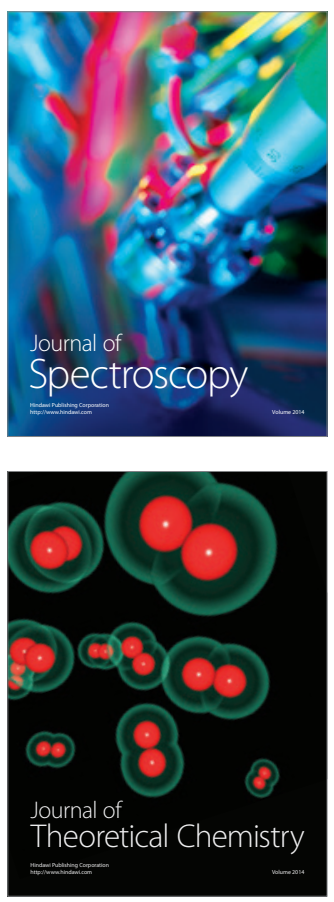
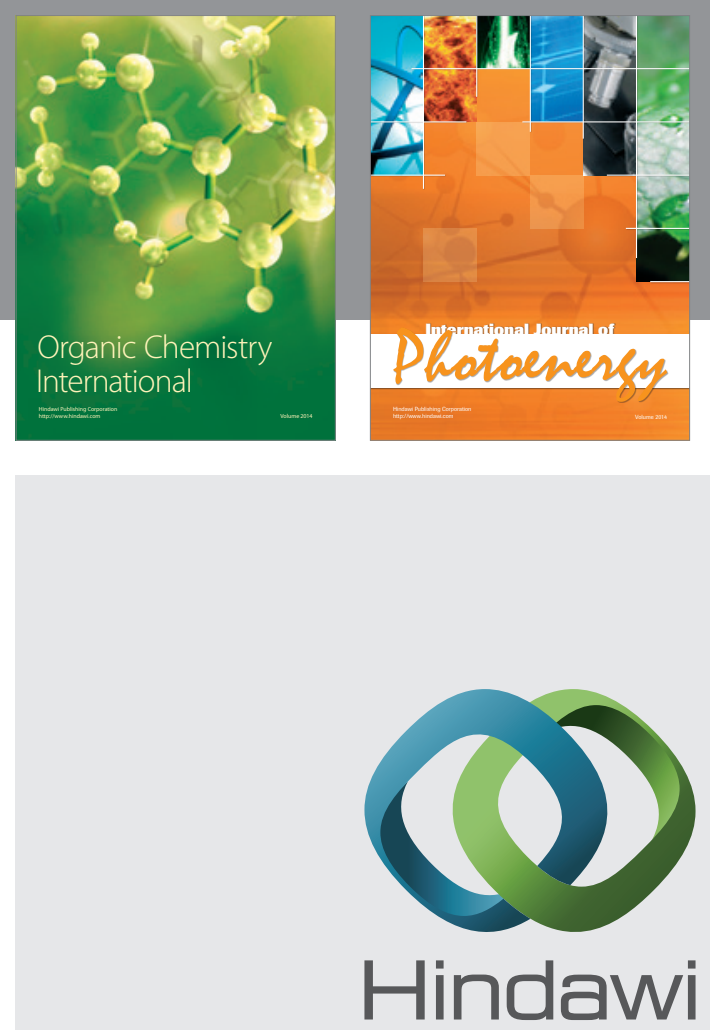

Submit your manuscripts at

http://www.hindawi.com
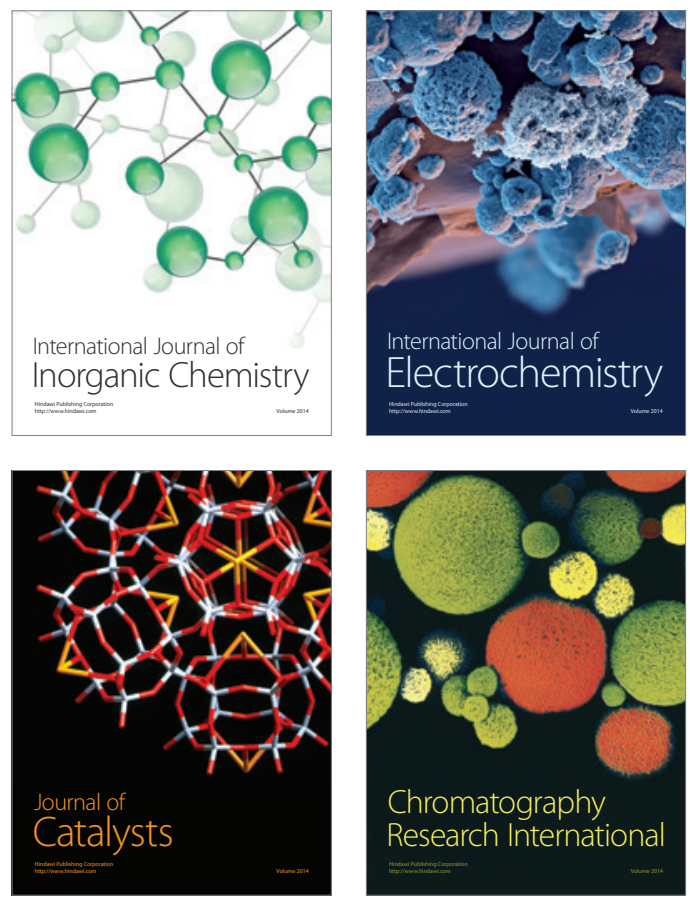
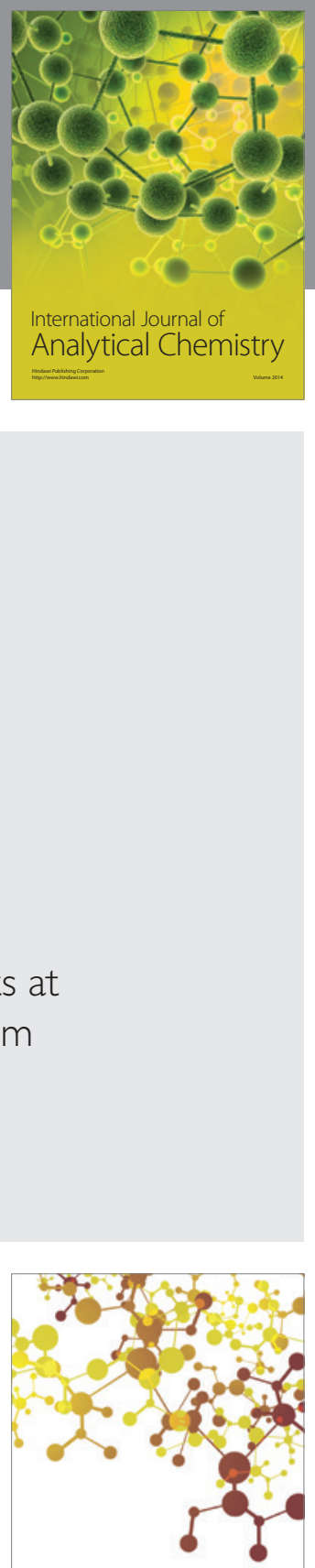

Journal of

Applied Chemistry
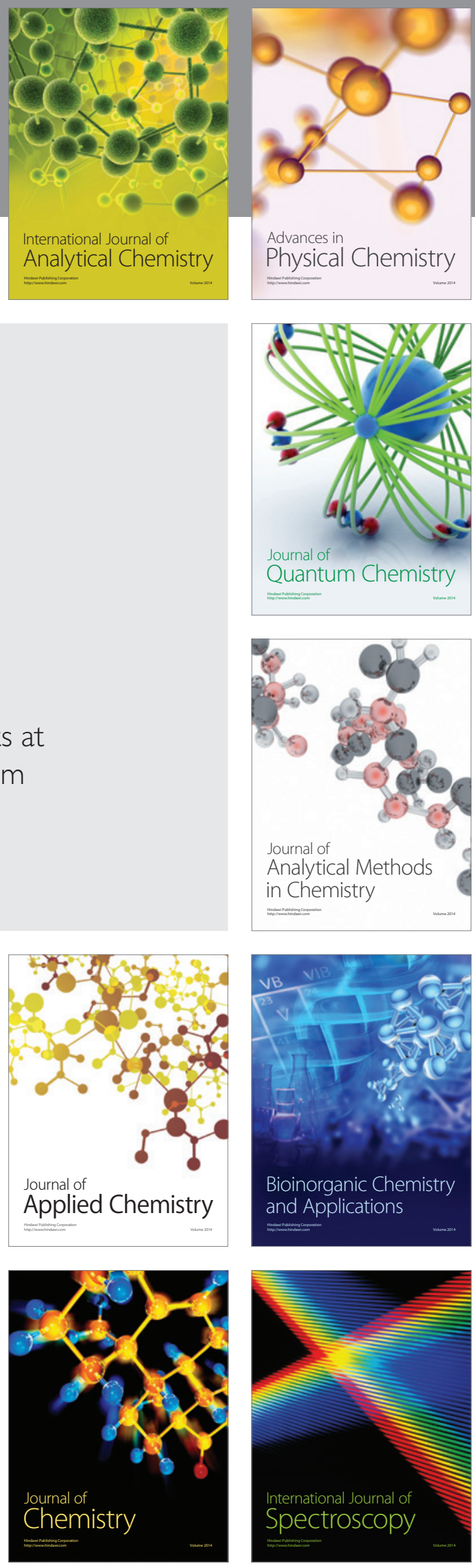